\section{Paralisia facial periférica bilateral na leucemia linfóide aguda: relato de caso}

\section{Bilateral peripheric facial nerve palsy in acute linfoid leukemia: a case report}

\author{
Marcos L. Antunes ${ }^{1}$, Maria C. M. Soares ${ }^{2}$, Andy $O$. \\ Vicente ${ }^{3}$, José R. G. Testa', Yotaka Fukudas
}

\section{Resumo / Summary}

\begin{abstract}
$\mathbf{A}$
mímica facial é fundamental para a expressão e comunicação humana, que são possíveis apenas através da integridade do nervo facial. Sendo assim, a paralisia facial periférica (PFP) pode deixar seqüelas estéticas, funcionais e psicológicas. A causa mais comum é a paralisia de Bell (50 a $80 \%$ ), onde a maioria dos pacientes apresenta manifestação unilateral. O acometimento bilateral simultâneo é raro, sendo a leucemia a neoplasia que com maior freqüência pode resultar nesse tipo de manifestação. A seguir, relatamos o caso de um paciente de dezoito anos de idade apresentando leucemia linfóide aguda (LLA) e PFP simultânea, ambas refratárias ao tratamento quimioterápico, culminando com o óbito cinco meses após o início da PFP. Realizou-se considerações importantes sobre a fisiopatologia da PFP na LLA, além de uma revisão da literatura.
\end{abstract}

Palavras-chave: leucemia, nervo facial, paralisia. Key words: leukemia, facial nerve, palsy.
T he facial mimic is very important to the human expression and communication, which depend on the integrity of the facial nerve. So, the peripheric facial palsy (PFP) can leave esthetics, functional and psychological sequelae. The more common etiology is Bell's palsy ( 50 to $80 \%$ ) and most of the patients show a unilateral manifestation. The simultaneous bilateral PFP is rare, and the leukemia is the neoplasia that can often that kind of manifestation. We present a clinical case of an 18-year-old patient with acute lymphoid leukemia and simultaneous bilateral facial palsy, who did not recover after the chemotherapy treatment, and died five months after the initial manifestation of the facial palsy. Important considerations were accomplished about the physiopathology of PFP in acute lymphoid leukemia, besides literature review.

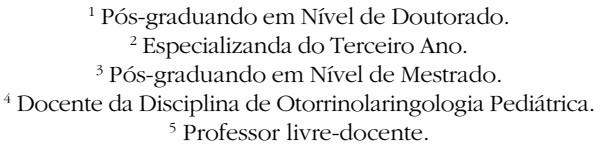

${ }^{5}$ Professor livre-docente.

Instituição: Departamento de Otorrinolaringologia e Distúrbios da Comunicação Humana.Universidade Federal de São Paulo-UNIFESP-EPM

Endereço para Correspondência: Maria Claudia M. Soares - R. Prof. Zoraide de Campos Helú, 04 Ipiranga São Paulo SP $04265-020$ E-mail: mcms26@aol.com

Trabalho apresentado como pôster no $36^{\circ}$ Congresso Brasileiro de Otorrinolaringologia-Florianópolis, Nov. 2002.

Artigo recebido em 20 de dezembro de 2002. Artigo aceito em 13 de fevereiro de 2003. 


\section{INTRODUCÃ̃}

A paralisia facial periférica é uma entidade não rara que pode deixar seqüelas estéticas e funcionais importantes nos pacientes. De acordo com a literatura, a paralisia de Bell é a causa mais comum, representando de 50 a $80 \%$ dos casos $^{1}$. Porém deve ser considerada como diagnóstico de exclusão. A maioria dos pacientes acometidos por paralisia facial periférica apresenta manifestação unilateral. O acometimento bilateral simultâneo do nervo facial é raro (menos de $1 \%$ dos casos de paralisia facial periférica) ${ }^{2,3}$.

Em uma revisão da literatura em mais de 2850 pacientes com paralisia facial periférica, foram encontradas mais de 90 etiologias diferentes, divididas em causas ao nascimento, traumas, causas neurológicas, infecções, causas metabólicas, neoplasias, causas tóxicas, iatrogênicas e idiopática (onde foi incluída a paralisia de Bell, que foi responsável por $51 \%$ dos casos). As causas tumorais foram responsáveis por apenas $6 \%$ dos casos ${ }^{4}$.

Dentre as causas tumorais, devemos nos lembrar dos tumores que lesam diretamente o nervo, como os tumores de parótida, o Schwannoma Vestibular, os tumores glômicos, entre outros, e as neoplasias com manifestação sistêmica podendo levar a um quadro de paralisia facial unilateral ou bilateral, como a leucemia. Quando consideramos a paralisa facial bilateral, a leucemia é a neoplasia que com maior freqüência pode ter este tipo de manifestação $0^{5,6}$

A leucemia é reconhecida como entidade clínica há mais de 150 anos, desde as descrições de Virchow e Craigie e Bennett (1845). Dress, em 1945, foi o $1^{\circ}$ otologista que atentou às complicações otológicas da leucemia. As manifestações, segundo Paparella et al. ${ }^{1}$, são mais comuns nas formas agudas que nas crônicas das leucemias e, principalmente, na leucemia linfóide aguda, onde as manifestações podem atingir 50\% dos pacientes, dentre elas a paralisia facial, disacusia neurossensorial, infecções timpanomastoídeas, nistagmos e vertigem.

A leucemia linfóide aguda é a que mais comumente cursa com paralisia facial. A leucemia meníngea ocorre por linfócitos ou mielócitos neoplásicos no tecido aracnóide. A proliferação das células ocorre em paredes superficiais das veias e se estende através da superfície da aracnóide até as artérias emergentes, veias, arteríolas e vênulas que percorrem o cérebro. As células leucêmicas reduzem o calibre destes vasos produzindo hipoperfusão cerebral, podendo levar a meningites, com sintomas como cefaléia, vômitos, sinais meníngeos e papiledema. Devido ao fato de nervos cranianos passarem através das leptomeninges, eles e seus vasos podem ser comprimidos e danificados pela infiltração leucêmica, resultando em neuropatia ${ }^{1,7}$.

O diagnóstico da leucemia meníngea é através do encontro de células blásticas no líquor e geralmente ocorre o aumento de proteínas. Porém, como já citado anteriormente, um exame de líquor normal não descarta a possibi- lidade de paralisia facial como manifestação de reativação de uma leucemia, apesar de ser extremamente raro, ${ }^{5,8}$.

A seguir relatamos um caso de um paciente de 18 anos de idade com leucemia linfóide aguda e paralisia facial periférica bilateral simultânea.

\section{RELATO DE CASO}

I.P.B., 18 anos, sexo masculino. Paciente atendido no pronto-socorro do Hospital São Paulo com queixa de fraqueza, astenia, além de aparecimento de manchas pelo corpo (petéquias e equimoses) e inchaço em alguns locais do corpo (linfoadenomegalias) há um mês. No interrogatório complementar apresentava febre intermitente, emagrecimento ( $6 \mathrm{~kg}$ no período) e inapetência.

A.P.: nega contato com produtos químicos, nega internações pregressas e outras doenças.

A.F.: sem antecedentes importantes.

Exame Físico Geral: Regular estado geral, descorado +/+4, linfoadenomegalia cervical. Diminuição de murmúrio vesicular em hemitórax direito, baço palpável à $8 \mathrm{~cm}$ do rebordo costal esquerdo e fígado palpável à $5 \mathrm{~cm}$ do rebordo costal direito. Presença de equimoses em membros inferiores.

Exames Subsidiários: Hemoglobina $=12 \mathrm{mg} / \mathrm{dl}$; Plaquetas $=14000 ;$ Leucócitos $=27000 \mathrm{com} 80 \%$ de blastos de aspecto linfóide.

Raio X de tórax: alargamento do mediastino.

Mielograma: 40\% de blastos linfóides.

Conclusão: Leucemia Linfóide Aguda.

Realizou $1^{a}$ sessão de quimioterapia com o esquema BFM5/93 (Daunorrubicina, Metrotexate, Elspar e Prednisona), recebendo alta um mês após a $1^{a}$ sessão, com remissão do quadro.

Evoluiu com pancreatite decorrente do Elspar, dois dias após a alta, e conseqüente diabete descompensada, sendo novamente internado. Realizou tomografia de abdômen que evidenciou pseudocisto de pâncreas, drenado por via endoscópica. Nesta ocasião apresentou um quadro súbito de paralisia facial periférica à esquerda. O teste prognóstico de Hilger mostrou diferença de $2 \mathrm{~mA}$ entre o lado normal e o paralisado. Introduzido aciclovir 1,5 gr/dia e prednisona $60 \mathrm{mg} /$ dia. Paciente não conseguiu realizar audiometria devido ao seu estado geral comprometido e iniciou supuração nas duas orelhas simultaneamente.

Realizou tomografia de crânio e ossos temporais, observado cisto em leptomeninge e velamento parcial das células mastóideas e da cavidade timpânica bilateral, com cadeia ossicular íntegra e sem lesão aparente do canal do nervo facial (Figuras 1 e 2).

Após três dias do quadro de paralisia facial à esquerda, apresentou paralisia facial periférica à direita, sendo de grau IV bilateralmente. O teste de Hilger mostrava resposta em $8 \mathrm{~mA}$ à direita e inexcitabilidade à esquerda. $\mathrm{O}$ exame de líquor nesta ocasião apresentava proteínas $=34$; glicose $=$ 
51 e 5973 células com 75\% de blastos e 25\% de linfócitos, comprovando a infiltração do sistema nervoso central. Iniciado esquema de quimioterapia intra-tecal, além de QT endovenosa (Hyper -C -VAD) evoluindo com melhora clínica e laboratorial, porém com persistência da paralisia facial, que evoluiu para grau $V$ após alguns dias, com paciente já se queixando de tinnitus e vertigens.

Realizada avaliação da neurologia que fez diagnóstico de polirradiculoneurite secundária à infiltração leucêmica (paciente com déficit motor generalizado). O paciente recebeu imunoglobulina humana hiperimune $400 \mathrm{mg} / \mathrm{kg} / \mathrm{dia}$ por 5 dias, porém sem melhora da paralisia. Apesar das tentativas de tratamento, o paciente foi a óbito 5 meses após o quadro de paralisia inicial, por septicemia.

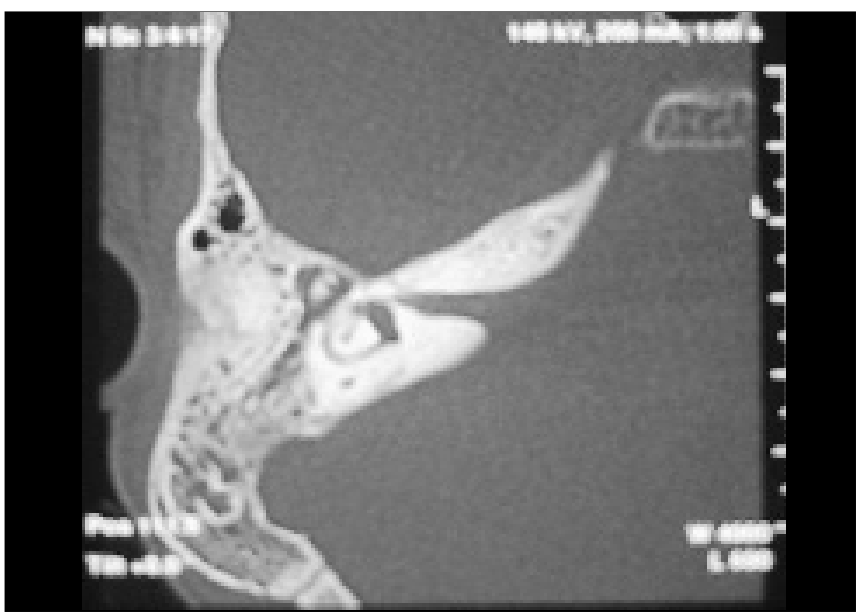

Figura 1. Corte tomográfico de osso temporal E

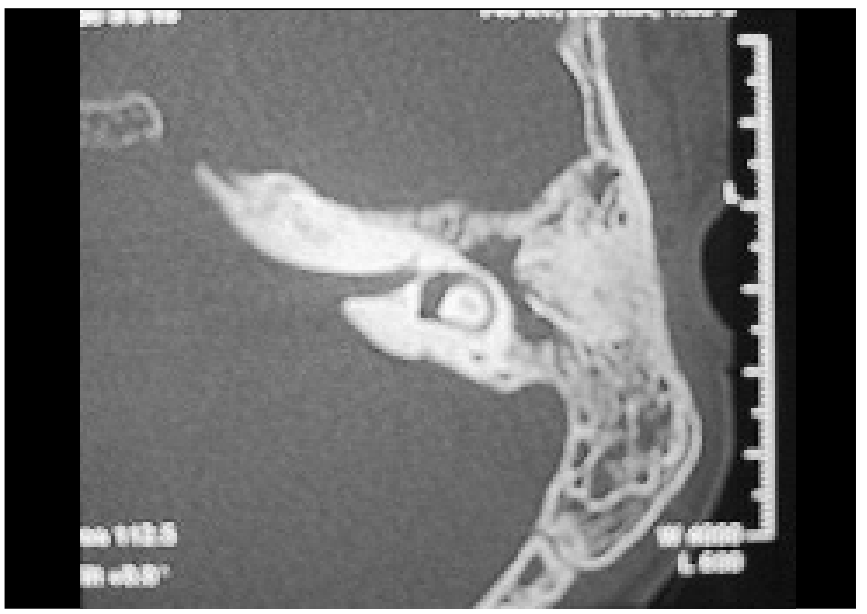

Figura 2. Corte tomográfico de osso temporal D

\section{DISCUSSÃO}

A paralisia facial periférica bilateral simultânea é rara (menos de 1\% das PFP) e dentre os diagnósticos diferenciais estão as causas traumáticas, a sífilis, Bell, síndrome de GuillainBarré, neuropatias múltiplas, encefalites, síndrome de Miller Fisher, tumores, moléstia de Hansen, criptococose (Aids), meningite tuberculosa, diabetes mellitus, sarcoidose, lupus, doença de Lyme, mononucleose, poliomielite,além de outras menos citadas na literatura, todos com uma freqüência extremamente pequena ${ }^{2,3}$.

A maioria dos pacientes com leucemia e paralisia facial apresenta células leucêmicas no líquor ou atividade da doença em outros órgãos. A paralisia facial como manifestação única de reativação leucêmica é muito rara ${ }^{5}$. Cartwright et al. reportaram oito casos de leucemia ou linfoma precedido por paralisia de Bell em estudos retrospectivos. Em quatro pacientes a paralisia precedeu em menos de um ano e destes, dois apresentaram apenas em um mês. A paralisia poderia ocorrer devido à infiltração de células malignas do nervo antes dos sinais e sintomas usuais de leucemia ou linfoma. Poderia ser o nervo facial um sítio de manutenção das células leucêmicas, que se multiplicariam, levando a um quadro de reativação? Neste caso, a paralisia deveria regredir com a regressão da infiltração blástica após o tratamento adequado.

No nosso paciente, a paralisia ocorreu aproximadamente três meses após as primeiras manifestações da doença, o que é mais comum de ocorrer, ou seja, as manifestações sistêmicas da doença geralmente precedem o aparecimento de paralisia facial.

Paparella et al. ${ }^{1}$ encontraram infiltração leucêmica, hemorragia e infecção em 45 ossos temporais de 25 pacientes com vários tipos de leucemia, obtidos em autópsia. A infiltração muitas vezes se estendia até os VII e VIII pares cranianos, fundo do meato acústico interno e algumas vezes até o labirinto membranoso. Dentre os achados histopatológicos, a infiltração leucêmica e o grau de infiltração foram os que tiveram maior relação com as manifestações clínicas, quando comparados com a hemorragia e a infecção.

As manifestações otorrinolaringológicas que relatamos no nosso paciente foram várias, como a paralisia facial, infecção da orelha média com persistência da efusão, além dos sintomas cócleo-vestibulares. Estes achados vão de encontro com os relatos de Paparella ${ }^{1}$, no tocante às várias manifestações otorrinolaringológicas da doença, que não são raras.

A idade é um fator importante para o desenvolvimento de infiltração meníngea por células blásticas, sendo mais comum em crianças e pré-escolares, provavelmente devido ao fato da maior relação entre circulação sanguínea e tecido cerebral quando comparado com adolescentes e adultos jovens. Quando a infiltração ocorre, a sobrevida diminui consideravelmente e a melhor terapia, de acordo com 
a literatura, seria a quimioterapia endovenosa em doses completas associada à quimioterapia intratecal e a radioterapia meníngea. As drogas mais comumente usadas para a quimioterapia endovenosa são a ciclofosfamida, a doxorrubina, a vincristina, a citosina arabinosídeo, a asparagina e a prednisona. A quimioterapia intratecal é geralmente realizada com o metrotexate . $^{8}$

Em um relato de caso de um paciente de 14 anos, o qual teve paralisia facial bilateral simultânea com intervalo de 16 dias entre o aparecimento da lesão unilateral para bilateral, o líquor não mostrava células blásticas, mas aumento de proteínas. Após o paciente apresentar sintomas como cefaléia, aumento de linfonodos e otalgia, foi repetido o líquor e então se encontraram células blásticas e no mielograma, 60\% de linfoblastos. O mesmo paciente melhorou da paralisia após dois meses da remissão pela quimioterapia, mas faleceu dois meses depois. Isto demonstra que realmente o prognóstico do paciente é pior quando ocorre manifestação de infiltração leucêmica na meninge.

Em um estudo de 62 pacientes com LLA, entre 1975 e 1978, apenas seis desenvolveram paralisia facial unilateral, sem infecção da orelha ou envolvimento de outros pares cranianos, todos faleceram entre seis meses após o evento, com uma média de quatro meses?.

O nosso paciente não apresentou melhora da paralisia facial mesmo após os vários tratamentos clínicos instituídos, porém pelas complicações inerentes ao próprio tratamento, não se conseguiu uma remissão completa da doença por um período satisfatório. Após a infiltração leucêmica do sistema nervoso central, a resposta ao tratamento não foi muito efetiva, observando-se um incremento dos sintomas relacionados a tal infiltração como as manifestações vestibulares e a polirradiculoneurite. $O$ paciente faleceu cinco meses após o início da paralisia facial, período similar aos casos relatados anteriormente.

\section{CONCLUSÃO}

A paralisia facial bilateral simultânea é muito rara e a leucemia está entre seus diagnósticos diferenciais, podendo, em alguns casos, ser uma manifestação isolada de reativação da doença. É comum o aparecimento de células blásticas e o aumento de proteínas no líquor, mas quando não houver o encontro de células neoplásicas não se descarta a possibilidade de infiltração meníngea levando à paralisia facial periférica.

A idade é um fator importante para a ocorrência de infiltração meníngea e esta última geralmente indica um pior prognóstico da doença de base. A paralisia facial pode apresentar recuperação após a remissão da infiltração blástica, porém a toxicidade das drogas pode ser fator limitante ao tratamento, podendo deixar seqüelas evidentes da paralisia facial.

\section{REFERÊNCIAS BIBLIOGRÁFICAS}

1. Morgan M, Nathwani D. Facial Palsy and Infection: The Unfolding Story CID 1992; 14: 263-71.

2. Keane JR. Bilateral seventh nerve palsy: Analysis of 43 cases and review of the literature. Neurology 1994; 44:1198-204.

3. Wormald PJ, Sellars SL, De Villiers JC. Bilateral facial nerve palsies Groote Schuur Hospital experience. J Laryngol Otol 1991; 105: 625-7.

4. May M, Klein S. Differential Diagnosis of Facial Nerve Palsy. In: Management of Facial Nerve Disorders- Otolaryngologic Clinics of North America 1991; 24:613-45.

5. Juhn YJ, Inoue S. Facial Nerve Palsy as an Early Manifestation of Relapse in T-Cell Acute Lymphoblastic Leukemia. Ear Nose \&Throat Journal 1996; 75:157-60

6. Paparella MM, Berlinger NT, Oda M, Fiky FE. Otological Manifestations of Leukemia. Laryngoscope 1973; 13:1510-26.

7. Sawada H, Matsui M, Udaka F, Nishimura M, Fujita M, Kameyama K. Adult T-Cell Leukemia Initially Manifesting as Facial Diplegia. American Journal of Hematology 1989; 32:61-5.

8. Pinkel D, Woo S. Prevention and Treatment of Meningeal Leukemia in Children. Blood 1994; 84:355-66.

9. Lilleyman JS, Antoniou AG, Sugden PJ. Facial Nerve Palsy in Acute Leukemia. Scan J Haematol 1979; 22:387-90. 